\title{
Predictors of success in selective laser trabeculoplasty for primary open angle glaucoma in Chinese
}

\author{
Jacky WY Lee ${ }^{1,2}$ \\ Catherine CL Liu ${ }^{3}$ \\ Jonathan $\mathrm{CH} \mathrm{Chan}{ }^{4}$ \\ Raymond LM Wong ${ }^{5}$ \\ lan YH Wong ${ }^{2}$ \\ Jimmy SM Lai
}

'The Department of Ophthalmology, Caritas Medical Centre, Hong Kong, SAR, People's Republic of China; ${ }^{2}$ The Department of Ophthalmology, The University of Hong Kong, Hong Kong, SAR, People's Republic of China;

${ }^{3}$ Department of Applied Mathematics, The Hong Kong Polytechnic

University, Hong Kong, SAR, People's Republic of China; ${ }^{4}$ The Department of Ophthalmology, Queen Mary Hospital, Hong Kong, SAR, People's Republic of China; ${ }^{5}$ The Department of Ophthalmology and Visual Sciences, Hong Kong Eye Hospital, Hong Kong, SAR, People's Republic of China

Correspondence: Jacky WY Lee The Department of Ophthalmology, Caritas Medical Centre, II I Wing Hong Street, Kowloon, Hong Kong, SAR, People's Republic of China

Tel +852 3408 79II

Fax +852 23070582

Email jackywylee@gmail.com
This article was published in the following Dove Press journal:

Clinical Ophthalmology

9 September 2014

Number of times this article has been viewed

Purpose: To determine the predictors of success for adjuvant selective laser trabeculoplasty (SLT) in Chinese primary open angle glaucoma (POAG) patients.

Methods: This prospective study recruited Chinese subjects with unilateral or bilateral POAG currently taking medication to reduce intraocular pressure (IOP). All subjects received a single session of $360^{\circ} \mathrm{SLT}$ treatment and continued their medications for 1 month. SLT success was defined as IOP reduction $\geq 20 \%$ at 1 month. The following covariates were analyzed in both groups via univariate and multivariate analyses: age, sex, lens status, initial IOPs, post-SLT IOPs, number and type of medications, SLT shots and energy, and pre-SLT investigations.

Results: In 51 eyes of 33 POAG subjects, the success rate of SLT was $47.1 \%$. Certain groups of patients were associated with greater success using univariate analysis. These groups included the following: older age (coefficient $=0.1$; OR: $1.1 ; P=0.0003$ ), a higher pre-SLT IOP (coefficient $=0.3$; OR: $1.3 ; P=0.0005$ ), using four types of antiglaucoma medication (coefficient $=2.1$; OR: $8.4 ; P=0.005$ ), a greater degree of spherical equivalent (coefficient $=2.1$; OR: $8.4 ; P=0.005$ ), and the use of a topical carbonic anhydrase inhibitor (coefficient $=1.7$; OR: 6.0; $P=0.003)$. None of the covariates were significant using multivariate analysis.

Conclusion: Older age, a higher pretreatment IOP, using multiple antiglaucoma medications especially topical carbonic anhydrase inhibitor, and higher refractive errors were associated with greater SLT success.

Keywords: primary open angle glaucoma, selective laser trabeculoplasty, intraocular pressure, success, Chinese

\section{Introduction}

Selective laser trabeculoplasty (SLT) is an increasingly popular treatment for primary open angle glaucoma (POAG) because it is a simple office procedure that is effective and repeatable, with minimal downtime and few long-term side effects. ${ }^{1}$ However, some of biggest challenges of using SLT are in predicting which patients will respond, by how much, and for how long. The response rate ranges from $59 \%$ to $96 \%$, and the amount of intraocular pressure (IOP) reduction ranges from $18 \%$ to $40 \%$ over a 6-12 month period. ${ }^{1}$ Previously, factors that have been consistently reported to predict SLT success throughout the literature include no prior antiglaucoma medication use ${ }^{1-3}$ and a higher IOP before SLT. ${ }^{4}$ There is limited information in the literature investigating the predictors for SLT success in the Chinese population. Differences in angle pigmentation may affect the outcome of SLT, ${ }^{5}$ making predictive factors different in this population from Western counterparts. The aim of this study is to determine the predictors of adjuvant SLT success in a Chinese POAG population. 


\section{Methods}

This prospective cohort study sequentially recruited Chinese subjects from the ophthalmology clinic of a university hospital, Queen Mary Hospital, Hong Kong, Special Administrative Region, People's Republic of China, from September 2011 to September 2012. The study included subjects with POAG currently on antiglaucoma medication. SLT was offered as adjuvant therapy to these patients either to reduce polypharmacy or to achieve a lower target IOP based on their individual clinical needs. Subjects were excluded if they had preexisting corneal pathology or scars, previous argon laser trabeculoplasty or SLT treatment, or if they did not comply with follow-up visit requirements. There was no washout prior to SLT. A single session of SLT was performed by a single surgeon (JWYL) using a Q-switched neodymium-doped yttrium aluminium garnet (Nd:YAG) laser (Ellex Solo ${ }^{\mathrm{TM}}$; Ellex Medical Pty. Ltd., Adelaide, Australia), for $360^{\circ}$ in all patients with an initial energy of $0.8 \mathrm{~mJ}$ and titrated until bubble formation was just visible. For those with bilateral disease, both eyes were treated in the same laser session. In all treated eyes, a single drop of Alphagan ${ }^{\circledR}$ P (Allergan, Inc., Irvine, CA, USA) was instilled immediately after SLT. A dexamethasone $0.1 \%$ and Neomycin $0.5 \%$ combination eye drop (Dexoptic-N; Ashford Laboratories Pvt. Ltd., Mumbai, India) was used twice daily for 1 day and was continued for a few more days only if anterior chamber reaction was detected during follow-up. Patients returned for follow-up visits on day 1 and 1 week, 1 month, and 3 months after SLT. Patients continued the same antiglaucoma drug regime for the first month after SLT. Medications were subsequently titrated to achieve individual target pressures based on clinical requirements.

The following parameters were recorded during the study: age, sex, lens status (phakic or pseudophakic), presenting IOP without medication (obtained from medical records), pre-SLT IOP, post-SLT day 1 IOP, post-SLT 1 week IOP, number of types of antiglaucoma medications, number of SLT shots, and average laser energy used. In addition, we measured pre-SLT average retinal nerve fiber layer (RNFL) via a Spectralis ${ }^{\circledR}$ optical coherence tomography, pre-SLT visual field index (VFI) on a Humphrey Field Analyzer (Humphrey Instruments, Inc., San Leandro, CA, USA), pre-SLT endothelial cell count via a noncontact specular microscopy (Noncon ROBO-CA; Konan Medical USA Inc., Irvine, CA, USA), pre-SLT central corneal thickness via videokeratography (Orbscan ${ }^{\circledR}$ IIz; Bausch \& Lomb Incorporated, Bridgewater, NJ, USA), pre-SLT
Snellen visual acuity, and pre-SLT spherical equivalent via kerato-refractometer (Topcon KR-8900; Topcon Europe Medical B.V., Capelle aan den IJssel, the Netherlands). We recorded the type of antiglaucoma eye drops that patients used pre-SLT, including beta-blockers, carbonic anhydrase inhibitors, prostaglandin analogs, alpha agonists, or pilocarpine. All IOP readings were measured via Goldmann applanation tonometry by a single investigator, and trained optometrists measured all other ocular parameters. Subjects were asked to return for follow-up at approximately the same time intervals during the day to minimize the effect of diurnal IOP fluctuation.

This study adhered to the tenets of the Declaration of Helsinki. Informed patient consent and approval by the institutional review board were obtained prior to study commencement. The authors declare no financial or proprietary interests.

\section{Definition of success}

The definition of SLT success was determined as $\geq 20 \%$ IOP reduction at 1 month after SLT as compared to the pre-SLT IOP. The 1-month post-op IOP was selected for continuity since all antiglaucoma medications were kept unchanged until then. Antiglaucoma medications were titrated to achieve individual target pressures, so the IOPs measured beyond 1 month were not solely representative of the efficacy of SLT.

\section{Statistics}

The association of the 24 covariates (Table 1) with SLT success was analyzed using univariate logistic analysis and multiple regression analysis. The high collinearity among the covariates hindered the interpretation of traditional multiple logistic regression. To overcome this, variable selection by elastic net approach was first conducted to remove redundant covariates where the estimates of coefficients equaled to zero prior to multiple regression analysis.

We performed both the univariate and multivariate regression analyses for the following three datasets separately: 1) both eyes, 2) right eyes only, and 3) left eyes only. We found that the significant variables detected from the right and left eyes were different, signifying that each eye has a unique underlying distribution that was different from the fellow eye. Furthermore, the analysis using data from both eyes was more comprehensive in including all variables that were significant than using just the right or left eye alone. Hence, we adopted the methodology of including both eyes in the dataset as this revealed all the possible significant variables. 
Table I Univariate and multivariate regression analyses of the covariates affecting SLT success in POAG

\begin{tabular}{|c|c|c|c|c|c|c|c|c|}
\hline & \multicolumn{4}{|c|}{ Univariate logistic analysis } & \multicolumn{4}{|c|}{ Multiple regression } \\
\hline & $P$-value & $\begin{array}{l}\text { Coefficient } \\
\text { estimates }\end{array}$ & $\begin{array}{l}\text { Standard } \\
\text { deviation }\end{array}$ & $\begin{array}{l}\text { Odds } \\
\text { ratio }\end{array}$ & $P$-value & $\begin{array}{l}\text { Coefficient } \\
\text { estimates }\end{array}$ & $\begin{array}{l}\text { Standard } \\
\text { deviation }\end{array}$ & $\begin{array}{l}\text { Odds } \\
\text { ratio }\end{array}$ \\
\hline Age & $0.0003^{*}$ & 0.11 & 0.04 & 1.11 & 0.18 & 0.38 & 0.28 & 1.46 \\
\hline Sex & 0.79 & 0.15 & 0.57 & 1.17 & 0.15 & 3.73 & 2.56 & 41.59 \\
\hline Pseudophakic & 0.53 & -0.56 & 0.92 & 0.57 & 0.20 & -7.49 & 5.83 & 0.00 \\
\hline Phakic & 0.83 & -0.12 & 0.57 & 0.89 & 0.66 & 1.11 & 2.51 & 3.05 \\
\hline $\begin{array}{l}\text { Presenting IOP (without } \\
\text { medication) }\end{array}$ & 0.80 & -0.02 & 0.06 & 0.98 & 0.28 & -0.39 & 0.36 & 0.68 \\
\hline Pre-SLT IOP & $0.0005 *$ & 0.28 & 0.09 & 1.32 & 0.11 & 1.10 & 0.69 & 3.01 \\
\hline Day I IOP post-SLT & 0.60 & 0.05 & 0.10 & 1.05 & 0.32 & -0.62 & 0.63 & 0.54 \\
\hline I week IOP post-SLT & 0.56 & 0.05 & 0.08 & 1.05 & 0.41 & 0.40 & 0.48 & 1.49 \\
\hline $\begin{array}{l}\text { I type of antiglaucoma } \\
\text { medication }\end{array}$ & 0.64 & -0.29 & 0.62 & 0.75 & 0.30 & 4.28 & 4.11 & 72.37 \\
\hline $\begin{array}{l}2 \text { type of antiglaucoma } \\
\text { medication }\end{array}$ & 0.17 & -0.98 & 0.75 & 0.38 & 0.36 & -3.35 & 3.67 & 0.04 \\
\hline $\begin{array}{l}3 \text { type of antiglaucoma } \\
\text { medication }\end{array}$ & 0.58 & -0.36 & 0.66 & 0.69 & \multicolumn{4}{|c|}{ Excluded from multivariate logistic analysis } \\
\hline $\begin{array}{l}4 \text { type of antiglaucoma } \\
\text { medication }\end{array}$ & $0.005^{*}$ & 2.12 & 0.85 & 8.36 & \multicolumn{4}{|c|}{ Excluded from multivariate logistic analysis } \\
\hline SLT shots & 0.38 & 0.01 & 0.01 & 1.01 & 0.99 & 0.00 & 0.16 & 1.00 \\
\hline SLT energy & 0.37 & 0.01 & 0.01 & 1.01 & 0.94 & 0.01 & 0.16 & 1.01 \\
\hline Pre-SLT RNFL & 0.18 & -0.02 & 0.02 & 0.98 & 0.96 & 0.00 & 0.06 & 1.00 \\
\hline Pre-SLT VFI on HVF & 0.09 & -0.02 & 0.01 & 0.98 & 0.24 & -0.09 & 0.07 & 0.92 \\
\hline $\begin{array}{l}\text { Pre-SLT endothelial cell } \\
\text { count }\end{array}$ & 0.90 & 0.00 & 0.00 & 1.00 & 0.16 & 0.00 & 0.00 & 1.00 \\
\hline $\begin{array}{l}\text { Pre-SLT central corneal } \\
\text { thickness }\end{array}$ & 0.54 & 0.00 & 0.01 & 1.00 & 0.18 & -0.05 & 0.04 & 0.95 \\
\hline Pre-SLT Snellen VA & 0.95 & -0.08 & 1.35 & 0.92 & 0.93 & 0.51 & 5.98 & 1.67 \\
\hline $\begin{array}{l}\text { Pre-SLT spherical } \\
\text { equivalent }\end{array}$ & $0.02 *$ & 0.18 & 0.09 & 1.19 & 0.50 & 0.20 & 0.30 & 1.22 \\
\hline $\begin{array}{l}\text { Pre-SLT use of } \\
\text { prostaglandin analogs }\end{array}$ & 0.02 & 1.61 & 0.73 & 5.00 & \multicolumn{4}{|c|}{ Excluded from multivariate logistic analysis } \\
\hline $\begin{array}{l}\text { Pre-SLT use of } \\
\beta \text {-blockers }\end{array}$ & 0.22 & 0.81 & 0.68 & 2.25 & \multicolumn{4}{|c|}{ Excluded from multivariate logistic analysis } \\
\hline $\begin{array}{l}\text { Pre-SLT use of carbonic } \\
\text { anhydrase inhibitors }\end{array}$ & $0.003^{*}$ & 1.79 & 0.62 & 5.98 & \multicolumn{4}{|c|}{ Excluded from multivariate logistic analysis } \\
\hline Pre-SLT use of $\alpha$ agonist & 0.63 & 0.29 & 0.61 & 1.33 & \multicolumn{4}{|c|}{ Excluded from multivariate logistic analysis } \\
\hline
\end{tabular}

Note: *Statistically significant.

Abbreviations: HVF, Humphrey visual field; IOP, intraocular pressure; POAG, primary open angle glaucoma; RNFL, retinal nerve fiber layer; SLT, selective laser trabeculoplasty; VA, visual acuity; VFI, visual field index.

Correlations were expressed in coefficients and odds ratio (OR), and a $P<0.05$ was considered statistically significant. All means were expressed as the mean \pm standard deviation.

\section{Results}

In 51 eyes of 33 subjects that were enrolled in the study, there were ten right eyes, five left eyes, and 18 subjects that received SLT bilaterally. The mean age was $62.4 \pm 11.5$ years. The mean IOP at initial presentation prior to starting antiglaucoma medication was $24.6 \pm 3.3 \mathrm{mmHg}$ with a pre-SLT IOP of $17.7 \pm 4.1 \mathrm{mmHg}$. Patients used $2.4 \pm 1.2$ types of eye drops prior to SLT. The mean of the SLT shots applied was $147.3 \pm 47.1$ per session using a mean power of $1.0 \pm 0.1 \mathrm{~mJ}$.
The mean IOP at 1 month after SLT was $13.8 \pm 3.3 \mathrm{mmHg}$, representing a mean overall IOP reduction of $17.9 \% \pm 20.0 \%$. The success rate of SLT was $47.1 \%(24 / 51)$.

Using univariate analysis, the following parameters were significantly associated with SLT success: older age (coefficient $=0.1$; OR: $1.1 ; P=0.0003$ ), a higher pre-SLT IOP (coefficient $=0.3$; OR: $1.3 ; P=0.0005$ ), using four types of antiglaucoma medication (coefficient $=2.1$; OR: 8.4; $P=0.005$ ), a higher spherical equivalent $($ coefficient $=2.1$; OR: 8.4; $P=0.005$ ), and the use of a topical carbonic anhydrase inhibitor (coefficient $=1.7$; OR: 6.0; $P=0.003$ ). On multivariate analysis, however, none of the covariates were found to influence SLT outcome significantly (Table 1). 


\section{Discussion}

In our population of medically treated Chinese POAG patients, a single session of adjuvant SLT achieved a mean IOP reduction of $18 \%$ with a response rate of $47 \%$. These results are slightly lower than the previously published IOP reduction range of $18 \%$ to $40 \%$ and success rate range of $59 \%$ to $96 \% .{ }^{1}$ We postulate that these differences are likely attributed to the fact that the pre-SLT IOP in our population was medically controlled with topical antiglaucoma medication prior to SLT $(17.7 \pm 4.1 \mathrm{mmHg}$ while on $2.4 \pm 1.2$ types of antiglaucoma eye drops). SLT was offered as adjuvant therapy to these patients either to reduce polypharmacy or to achieve a lower target IOP based on their individual clinical needs. We demonstrated that a higher pre-SLT IOP was associated with greater SLT success (OR: 1.32; $P=0.0005$ ). This finding was consistent with what has been previously reported for the Western population. ${ }^{4,6,7}$

The use of four types of antiglaucoma medications (OR: $8.36 ; P=0.005)$ and the prior use of a topical carbonic anhydrase inhibitor (OR: 5.98; $P=0.003$ ) were associated with greater SLT success. Those who required four types of antiglaucoma medication were more likely to have a higher pre-SLT IOP (hence necessitating more antiglaucoma medication). Therefore, this may be an indirect effect from a higher pre-SLT IOP. As for the type of antiglaucoma medication used, previous reports have demonstrated that prostaglandin eye drops can potentially hinder the effects of SLT. ${ }^{4}$ The positive association of carbonic anhydrase inhibitor use with SLT success has not been reported before. We postulate that it may not be the direct use of a topical carbonic anhydrase inhibitor that enhances SLT success but perhaps the use of this drug in place of a prostaglandin that accounts for this phenomenon, since prostaglandins can potentially counteract the action of metalloproteinase and macrophages in the trabecular meshwork following SLT. ${ }^{4}$

Older age was found to be a significant predictor for success (OR: $1.11 ; P=0.0003)$. This is contrary to the majority of reports in the literature that have found no significant association between age and SLT success..$^{8-10}$ Our finding was in agreement with that of Ahmed et al who also reported that age $\geq 60$ years was associated with greater success. ${ }^{11}$

Having a greater degree of spherical equivalent or more refractive error was also a predictor of SLT success (OR: 1.19; $P=0.02$ ). This association has not been reported before in the literature. This observation may be related to the association of myopia with POAG and the greater prevalence of myopia in our population compared to the Caucasian population. ${ }^{12,13}$ We postulate that those with more refractive errors (most likely myopia since the mean spherical equivalent in our population was $-3.54 \pm 4.05$ diopters) were more likely to have deeper anterior chamber angles and theoretically, more areas of trabecular meshwork that were open and visible for treatment. While angle status was not found to influence SLT success in the Western population where an open angle configuration is the norm, ${ }^{14}$ this situation may be different in a Chinese population with a higher prevalence of anatomically narrower angles. ${ }^{15}$ Thus, those with a deeper anterior chamber may have better trabecular meshwork exposure for SLT, as it has been reported that treatment to $360^{\circ}$ of the trabecular meshwork is far more superior to $180^{\circ}$ treatment, which in turn is still more superior to only $90^{\circ}$ of angle treatment. ${ }^{16}$

Our study had its limitations. Firstly, the 1-month IOP was used for the calculation of IOP response. A longer period following SLT would have been more ideal, but the decision was based on the following rationale: 1) patients were maintained on the same antiglaucoma medication regimen up to 1 month after SLT, hence the changes in IOP during this time would solely represent the effect of SLT, and 2) based on previous reports in the literature, the IOP-lowering effects of SLT at 2 weeks was predictive of the IOP results at 3 months after laser. ${ }^{17}$

Secondly, topical antiglaucoma medications were not washed out prior to SLT. The investigators felt that it would be unethical to stop antiglaucoma medication in the POAG group prior to laser as this would result in certain patients having a period of elevated IOP without medication. This decision was also based on previous reports in the literature confirming that eye drops use did not seem to influence SLT success significantly. ${ }^{6}$

\section{Conclusion}

Nevertheless, this is one of the few studies in the literature reporting the predictors of SLT success for a Chinese POAG population. It is also one of the first to report a positive association between SLT and the use of carbonic anhydrase inhibitor or a greater degree of spherical equivalent. In summary, SLT was successful in close to $50 \%$ of a sample of Chinese POAG patients. A higher pre-SLT IOP, using four types of antiglaucoma eye drops, use of a topical carbonic anhydrase inhibitor, older age, and higher refractive errors were predictors for SLT success.

\section{Disclosure}

The article processing charge was funded by Ellex Medical Pty. Ltd. The authors had sole autonomy over all aspects of the clinical research and write-up. The authors report no 
other conflicts of interest in this work. This work has not been published elsewhere and has not been submitted simultaneously for publication elsewhere.

\section{References}

1. Barkana Y, Belkin M. Selective laser trabeculoplasty. Surv Ophthalmol. 2007;52(6):634-654.

2. Melamed S, Ben Simon GJ, Levkovitch-Verbin H. Selective laser trabeculoplasty as primary treatment for open-angle glaucoma: a prospective, nonrandomized pilot study. Arch Ophthalmol. 2003;121(7):957-960.

3. Rachmiel R, Trope GE, Chipman ML, Gouws P, Buys YM. Laser trabeculoplasty trends with the introduction of new medical treatments and selective laser trabeculoplasty. J Glaucoma. 2006;15(4):306-309.

4. Song J, Lee PP, Epstein DL, et al. High failure rate associated with 180 degrees selective laser trabeculoplasty. J Glaucoma. 2005;14(5):400-408.

5. Harasymowycz PJ, Papamatheakis DG, Latina M, De Leon M, Lesk MR, Damji KF. Selective laser trabeculoplasty (SLT) complicated by intraocular pressure elevation in eyes with heavily pigmented trabecular meshworks. Am J Ophthalmol. 2005;139(6):1110-1113.

6. Mao AJ, Pan XJ, McIlraith I, Strasfeld M, Colev G, Hutnik C. Development of a prediction rule to estimate the probability of acceptable intraocular pressure reduction after selective laser trabeculoplasty in open-angle glaucoma and ocular hypertension. J Glaucoma. 2008;17(6):449-454.

7. Hodge WG, Damji KF, Rock W, Buhrmann R, Bovell AM, Pan Y. Baseline IOP predicts selective laser trabeculoplasty success at 1 year post-treatment: results from a randomised clinical trial. Br J Ophthalmol. 2005;89(9):1157-1160.

8. Ayala M, Chen E. Predictive factors of success in selective laser trabeculoplasty (SLT) treatment. Clin Ophthalmol. 2011;5:573-576.
9. Gracner T, Naji M, Hudovernik M, Gracner B, Pahor D. Die Vorhersagefaktoren einer erfolgreichen selektiven Lasertrabekuloplastik bei Offenwinkelglaukom [Predictive factors of successful selective laser trabeculoplasty in open-angle glaucoma]. Klin Monbl Augenheilkd. 2007;224(12):922-926. German.

10. Bruen R, Lesk MR, Harasymowycz P. Baseline factors predictive of SLT response: a prospective study. J Ophthalmol. 2012;2012:642869.

11. ASCRS Eyeworld. Ahmed IK, Angelucci, D. Best Paper of Session. Individual patient factors influence SLT success. Available from: http:// www.eyeworld.org/article.php?sid=2685. Accessed May 4, 2014.

12. Liang YB, Friedman DS, Zhou Q, et al; Handan Eye Study Group. Prevalence of primary open angle glaucoma in a rural adult Chinese population: the Handan eye study. Invest Ophthalmol Vis Sci. 2011; 52(11):8250-8257.

13. Lam CS, Lam CH, Cheng SC, Chan LY. Prevalence of myopia among Hong Kong Chinese school children: changes over two decades. Ophthalmic Physiol Opt. 2012;32(1):17-24.

14. Martow E, Hutnik CM, Mao A. SLT and adjunctive medical therapy: a prediction rule analysis. J Glaucoma. 2011;20(4):266-270.

15. Seider MI, Pekmezci M, Han Y, et al. High prevalence of narrow angles among Chinese-American glaucoma and glaucoma suspect patients J Glaucoma. 2009;18(8):578-581.

16. Nagar M, Ogunyomade A, O'Brart DP, Howes F, Marshall J. A randomised, prospective study comparing selective laser trabeculoplasty with latanoprost for the control of intraocular pressure in ocular hypertension and open angle glaucoma. Br J Ophthalmol. 2005; 89(11):1413-1417.

17. Johnson PB, Katz LJ, Rhee DJ. Selective laser trabeculoplasty: predictive value of early intraocular pressure measurements for success at 3 months. Br J Ophthalmol. 2006;90(6):741-743.
Clinical Ophthalmology

\section{Publish your work in this journal}

Clinical Ophthalmology is an international, peer-reviewed journa covering all subspecialties within ophthalmology. Key topics include: Optometry; Visual science; Pharmacology and drug therapy in eye diseases; Basic Sciences; Primary and Secondary eye care; Patient Safety and Quality of Care Improvements. This journal is indexed on

Submit your manuscript here: http://www.dovepress.com/clinical-ophthalmology-journal

\section{Dovepress}

PubMed Central and CAS, and is the official journal of The Society of Clinical Ophthalmology (SCO). The manuscript management system is completely online and includes a very quick and fair peer-review system, which is all easy to use. Visit http://www.dovepress.com/ testimonials.php to read real quotes from published authors. 